\title{
Leading IMIA through a Global Pandemic
}

\author{
Sabine Koch, President of IMIA \\ Karolinska Institutet, Stockholm, Sweden
}

When taking on the presidency of the International Medical Informatics Association (IMIA) in 2019, my greatest wish was to give not least the young generation of biomedical and health informaticians the possibility to collaborate, build networks, exchange ideas, and to provide a platform to perform new activities and expand them. I was thrilled about the Student and Emerging Professionals Special Interest Group that was formed at Medinfo 2019 in Lyon and hoped for cross fertilization with the International Academy of Health Sciences Informatics ("The Academy" for short), consisting of elected fellows with long standing academic achievements in the field.

What I certainly did not have in mind was the complete absence of physical meetings during my presidency. But new circumstances create new opportunities. Many of the core IMIA activities happen in the IMIA Working Groups (WGs) and Special Interest Groups (SIGs) that immediately switched their work towards the COVID-19 pandemic. Under the leadership of the Vice President for WG/SIG Luis Fernandez-Luque, the WG/SIG chairs prepared a call for action on Evidence-Based Health Informatics as the Foundation for the COVID-19 Response [1]. In this paper, thirteen out of twenty-six WGs and SIGs reported their efforts in helping to build an evidence-based response to this crisis; and more papers responding to this call for action are to come. Another COVID-19 related IMIA activity took place on December 16, 2020, when representatives of IMIA and IMIAs Academy held an open dialogue with the Director General of the World Health Organization (WHO), Dr. Tedros Adhanom Ghebreyesus, about the opportunities and challenges of digital health during the COVID-19 global pandemic. The dialogue attracted 200 participants from different civil society organizations and its outcomes have been published in the IMIA Yearbook [2], and are further incorporated into the new collaboration plan between IMIA and WHO.

\section{Virtual Medlnfo 2021}

As most other conferences during 2020 and 2021, also MedInfo 2021 will be held in an online format. Najeeb Al-Shorbaji as the Vice President MedInfo has together with the Scientific Program Committee Co-chairs Paula Otero and Philip Scott worked tirelessly to set up the first virtual MedInfo ever. This virtual meeting gives IMIA the possibility to strengthen its strategic goals regarding collaboration and membership, namely "to promote the cross-fertilization of health informatics knowledge and skills across academic, professional, and geographical boundaries", and "to strengthen opportunities for participation in the Association by all members, across all membership categories" [3]. The virtual MedInfo will be arranged solely by IMIA, and will consist mainly of pre-recorded presentations, and very few, time scheduled, synchronous panels taking different time zones into account. Presenters will get their papers published in the PubMed-indexed conference proceedings by IOS Press at a low cost, and attendance for non-presenters will be free of charge to enable broad participation.

Several other IMIA initiatives, in relation to the goals of the IMIA 2017 Strategic Plan [3], are ongoing, such as the revision of the IMIA Recommendations on Education under the leadership of the Vice President Special Affairs Jen Bichel-Findlay, and the development of new membership models led by the Vice President Membership Daniel Luna. The COVID-19 pandemic also forced us to change IMIA meeting traditions, and to shorten Board and General Assembly meetings from full day meetings to two hours. Filling these meetings with fruitful discussions and pursue administrative tasks online is something that I hope will continue also in the post pandemic era.

Some more changes in IMIA's governance structures will be needed to transform it into a more agile organization, and I am grateful to the members of the Executive Committee - Secretary Petter Hurlen, Treasurer Philip Robinson, President-Elect Yu-Chuan (Jack) Li, and CEO Elaine Huesing for supporting me with that during my Presidency, and I wish Jack Li as incoming President the best of luck to continue the renewal of IMIA.

\section{References}

1. Fernandez-Luque L, Kushniruk AW, Georgiou A, Basu A, Petersen C, Ronquillo C, et al. Evidence-Based Health Informatics as the Foundation for the COVID-19 Response: A Joint Call for Action. Methods Inf Med 2021 May 11. doi: 10.1055/s-0041-1726414. Epub ahead of print.

2. Koch S, Hersh WR, Bellazzi R, Leong TY, Yedaly M, Al-Shorbaji N. Digital Health during COVID-19: Informatics Dialogue with the World Health Organization. Yearb Med Inform 2021 Apr 21. doi: 10.1055/s-0041-1726480. Epub ahead of print.

3. IMIA Strategic Plan - Executive Summary, 2017 [cited 2021 June 27]. Available from: https:// imia-medinfo.org/wp/imia-strategic-plan/ 